\title{
Facial fractures and associated injuries in high-versus low-energy trauma: all are not created equal
}

Cameron St. Hilaire, Arianne Johnson, Caitlin Loseth, Hamid Alipour, Nick Faunce, Stephen Kaminski and Rohit Sharma* ${ }^{*}$

\begin{abstract}
Introduction: Facial fractures (FFs) occur after high- and low-energy trauma; differences in associated injuries and outcomes have not been well articulated.

Objective: To compare the epidemiology, management, and outcomes of patients suffering FFs from high-energy and low-energy mechanisms.

Methods: We conducted a 6-year retrospective local trauma registry analysis of adults aged 18-55 years old that suffered a FF treated at the Santa Barbara Cottage Hospital. Fracture patterns, concomitant injuries, procedures, and outcomes were compared between patients that suffered a high-energy mechanism (HEM: motor vehicle crash, bicycle crash, auto versus pedestrian, falls from height $>20$ feet) and those that suffered a low-energy mechanism (LEM: assault, ground-level falls) of injury.
\end{abstract}

Results: FFs occurred in 123 patients, 25 from an HEM and 98 from an LEM. Rates of Le Fort (HEM 12\% vs. LEM 3\%, $P=$ 0.10 ), mandible (HEM 20\% vs. LEM 38\%, $P=0.11$ ), midface (HEM 84\% vs. LEM 67\%, $P=0.14$ ), and upper face (HEM $24 \%$ vs. LEM $13 \%, P=0.217)$ fractures did not significantly differ between the HEM and LEM groups, nor did facial operative rates (HEM $28 \%$ vs. LEM 40\%, $P=0.36$ ). FFs after an HEM event were associated with increased Injury Severity Scores (HEM 16.8 vs. LEM 7.5, $P<0.001$ ), ICU admittance (HEM 60\% vs. LEM 13.3\%, $P<0.001$ ), intracranial hemorrhage (ICH) (HEM $52 \%$ vs. LEM 15\%, $P<0.001$ ), cervical spine fractures (HEM 12\% vs. LEM 0\%, $P=0.008$ ), truncal/lower extremity injuries (HEM 60\% vs. LEM 6\%, $P<0.001$ ), neurosurgical procedures for the management of ICH (HEM 54\% vs. LEM $36 \%, P=0.003$ ), and decreased Glasgow Coma Score on arrival (HEM 11.7 vs. LEM 14.2, $P<0.001$ ).

Conclusion: FFs after HEM events were associated with severe and multifocal injuries. FFs after LEM events were associated with $\mathrm{ICH}$, concussions, and cervical spine fractures. Mechanism-based screening strategies will allow for the appropriate detection and management of injuries that occur concomitant to FFs.

Type of study: Retrospective cohort study.

Level of evidence: Level III.

Keywords: Facial fractures, High-energy mechanisms, Low-energy mechanisms, Outcomes

*Correspondence: rsharma@sbch.org

Santa Barbara Cottage Hospital, Santa Barbara, California, USA

(c) The Author(s). 2020 Open Access This article is licensed under a Creative Commons Attribution 4.0 International License, which permits use, sharing, adaptation, distribution and reproduction in any medium or format, as long as you give appropriate credit to the original author(s) and the source, provide a link to the Creative Commons licence, and indicate if changes were made. The images or other third party material in this article are included in the article's Creative Commons licence, unless indicated otherwise in a credit line to the material. If material is not included in the article's Creative Commons licence and your intended use is not permitted by statutory regulation or exceeds the permitted use, you will need to obtain permission directly from the copyright holder. To view a copy of this licence, visit http://creativecommons.org/licenses/by/4.0/. 


\section{Introduction}

Dating back to the foundational work of Rene Le Fort, facial fractures (FFs) are recognized as an important source of morbidity after injury and are often associated with significant concomitant trauma [1]. Seemingly lowenergy mechanisms (LEMs) such as assaults or groundlevel falls can often lead to considerable craniofacial injuries, and high-energy mechanisms (HEMs) such as motor vehicle or bicycle crashes can leave clinicians managing major multisystem trauma alongside the FFs. Due to the innate biomechanics of the craniofacial bones, similar FF patterns can occur after a wide spectrum of traumatic forces, and so it is often times unclear what diagnostic tests are warranted in order to detect concomitant injuries and guide management decisions [2]

There have been a limited number of studies comparing the differences in fracture patterns, concomitant injuries, and management of patients with FFs following an LEM or HEM event. Prior studies describing patient outcomes after a FF often grouped heterogeneous mechanisms of injury (MOIs) together when evaluating mortality rates, airway management needs, or rates of intracranial hemorrhage ( $\mathrm{ICH})$ [3-7]. Grouping together both high-energy and low-energy MOIs, however, risks missing potential differences in injuries and outcomes between the two groups. A more granular understanding of injury patterns and outcomes can be obtained with mechanismspecific comparative analyses and, in an era when utilizing evidence-based screening protocols are of paramount importance, can better guide imaging and management decisions $[8,9]$. In order to better differentiate the injuries and outcomes in patients with FFs after various MOIs, we evaluated fracture patterns, concomitant injuries, procedures required, timing of procedures, and outcomes in patients presenting with FFs after LEMs and HEMs.

\section{Methods}

After Institutional Review Board approval, we conducted a retrospective review of patient records maintained in our trauma registry at the Santa Barbara Cottage Hospital $(\mathrm{SBCH}) . \mathrm{SBCH}$ is an academic teaching hospital, regional referral center, and an American College of Surgeons verified Level-1 Trauma Center in Santa Barbara, CA. We identified all adult patients aged 18-55 years old evaluated at $\mathrm{SBCH}$ for facial fractures (ICD-9 Codes 802.0-802.9 and 804.0-804.9, ICD-10 Codes S02.2-S02.9) from January 2013 to April 2019. Patients were then classified into LEM or HEM, defined by MOI (Table 1). Statistical analysis was performed using $\mathrm{R}$ Version 3.5.1 [10]. Patient demographics, comorbidities, FF region, concomitant injuries, procedures performed, and mortality rates were compared using Fisher's exact test of independence. FFs were divided into upper face (supraorbital rim, orbital roof, frontal bone, frontal sinus), midface (nasal,
Table 1 Mechanisms of injury

\begin{tabular}{ll}
\hline \multicolumn{1}{c}{ Low energy $(\boldsymbol{n}=\mathbf{9 0})$} & \\
\hline Assault (\%) & $64(65.3)$ \\
Ground-level fall (\%) & $14(14.3)$ \\
Bicycle/skateboard crash (\%) & $12(12.2)$ \\
Sports-related (\%) & $5(5.1)$ \\
Work-related (\%) & $2(2.0)$ \\
Self-inflicted (blunt head injury) (\%) & $1(1.0)$ \\
$\quad$ High energy ( $\boldsymbol{n}=\mathbf{2 5})$ & \\
Fall from height >20 feet (\%) & $13(52.0)$ \\
Motor vehicle crash (\%) & $5(20.0)$ \\
Auto vs. pedestrian (\%) & $4(16.0)$ \\
Motorcycle crash (\%) & $2(8.0)$ \\
Gunshot to face (\%) & $1(4.0)$ \\
\hline
\end{tabular}

maxillary, zygomatic, orbital wall, ethmoid, dentoalveolar bones), and those involving the mandible. Injury severity score (ISS), hospital length of stay (LOS), intensive care unit (ICU) LOS, and number of days from admission until operation for patients that underwent surgery were compared using an independent two-sample Mann-Whitney $U$ test.

\section{Results}

We identified 123 patients with FFs, 98 (80\%) were due to LEMs, and 25 (20\%) were from HEMs. There were no significant differences in sex, age, history of osteoporosis, pre-injury steroid or tobacco use, mean calcium or albumin levels, or anticoagulant use. The most common LEMs were assault (65\%), ground-level falls (14\%), and bicycle/skateboard crashes (12\%). The most common HEMs were falls from height $>20$ feet $(6 \mathrm{~m})(52 \%)$, motor vehicle crashes (20\%), and auto-versus pedestrian crashes (16\%). Over half (54\%) of LEM patients tested positive for ethanol in contrast to only $22 \%$ of HEM patients $(P=$ 0.024). HEM patients had a longer overall LOS (HEM 14 days vs. LEM 4 days, $P<0.001$ ), longer ICU LOS (HEM 12 days vs. LEM 4 days, $P=0.011$ ), greater burden of injury based on ISS (HEM 16.8 vs. LEM 7.5, $P<0.001$ ), and subsequently higher ICU admission rates (HEM 60\% vs. LEM $13 \%, P<0.001)$. Table 2 summarizes patient demographics, comorbidities, and outcomes.

FF patterns were compared, and we found no differences in rates of upper face (HEM 24\% vs. LEM 13\%, $P$ $=0.217$ ), midface (HEM 84\% vs. LEM 63\%, $P=0.057$ ), mandible (HEM 20\% vs. LEM 38\%, $P=0.105$ ), Le Fort (HEM $12 \%$ vs. LEM 3\%, $P=0.098$ ), or bilateral fractures (HEM 32\% vs. LEM 17\%, $P=0.161$ ). Facial surgeries were required in $40 \%$ of LEM patients and in $28 \%$ of HEM patients $(P=0.357)$. The most common procedures in 
Table 2 Patient demographics, comorbidities, and outcomes

\begin{tabular}{|c|c|c|c|}
\hline & Energy mechanism & & $P$ value \\
\hline & Low $(n=98)$ & High $(n=25)$ & \\
\hline Age $(S D)^{1}$ & $32.4(12.6)$ & $4.9(13.1)$ & 0.489 \\
\hline Number of males $(\%)^{2}$ & $87(88.8)$ & $19(76.1)$ & 0.18 \\
\hline History of osteoporosis (\%) ${ }^{2}$ & 0/97 (0) & $0(0)$ & NA \\
\hline Pre-injury steroid use (\%) ${ }^{2}$ & $1 / 97(1)$ & $0(0)$ & 1 \\
\hline Pre-injury tobacco use (\%) ${ }^{2}$ & 26/97 (27) & $5(20)$ & 0.661 \\
\hline Pre-injury anticoagulant use $(\%)^{2}$ & $0(0)$ & $2(8)$ & 0.053 \\
\hline Calcium levels (SD) ${ }^{1}$ & $9.0(0.7), n=95$ & $9.0(0.6)$ & 0.819 \\
\hline Albumin levels (SD) ${ }^{1}$ & $4.3(0.4), n=95$ & $4.3(0.7)$ & 0.211 \\
\hline Positive ethanol $(\%)^{2}$ & $44 / 82(54)$ & $5 / 24(22)$ & $0.012^{*}$ \\
\hline Hospital LOS—days (SD) ${ }^{1}$ & $4(4), n=67$ & $14(12), n=23$ & $<0.001^{*}$ \\
\hline ICU LOS—days (SD) ${ }^{1}$ & $4(3), n=13$ & $12(10), n=15$ & $0.011^{*}$ \\
\hline ICU admittance $(\%)^{2}$ & $13(13)$ & $15(60)$ & $<0.001^{*}$ \\
\hline Needing ventilator (\%) ${ }^{2}$ & $8(8)$ & $12(48)$ & $<0.001^{*}$ \\
\hline Days on ventilator (SD) ${ }^{1}$ & $4.7(6.5)$ & $10.7(7.7)$ & 0.081 \\
\hline ISS (SD) ${ }^{1}$ & $7.5(6.3)$ & $16.8(9.8)$ & $<0.001^{*}$ \\
\hline GCS (SD) ${ }^{1}$ & $14.2(2.1)$ & $11.7(4.2)$ & $0.002^{*}$ \\
\hline Mortality $(\%)^{2}$ & $1(1)$ & $1(4)$ & 0.367 \\
\hline
\end{tabular}

${ }^{1}$ Two-sample Mann-Whitney $U$ test

${ }^{2}$ Fisher's exact $T$ test

each group were to repair mandible fractures (HEM 43\%, LEM 85\%). Nearly one quarter of mandible fractures in the LEM group were managed solely with intermaxillary fixation (IMF); in contrast, none of the FFs in the HEM group were managed using IMF. The median hospital day when facial procedures were performed was similar between the two groups (HEM day 2 vs. LEM day $1, P=0.086$ ).

Computed tomographic angiography (CTA) rates were lower in the LEM group (HEM 36\% vs. LEM 5\%, $p<0.001$ ), but no cerebrovascular injuries were found in either group. Patients with HEM injuries presented with lower mean Glasgow Coma Scores (GCS) (HEM 11.7 vs. LEM $14.2, P=0.002)$, higher rates of ICH (HEM $52 \%$ vs. LEM $15 \%, p<0.001)$, and more often required neurosurgical procedures (HEM $54 \%$ vs. LEM $36 \%, P=0.003$ ). HEM patients had higher rates of torso/extremity injuries (HEM $64 \%$ vs. LEM $7 \%, P=0.045$ ), and specifically, higher rates of cervical spine fractures (HEM $12 \%$ vs. LEM $0 \%, P=$ 0.008 ), thoracic injuries (HEM $56 \%$ vs. LEM $5 \%, p<0.001$ ), abdominal injuries (HEM 8\% vs. LEM 0\%, $P=0.04$ ), and pelvic lower extremity injuries (HEM $24 \%$ vs. LEM $1 \%, P$ $=0.034)$. The HEM group had higher rates of surgical procedures of any kind (HEM $72 \%$ vs. LEM $49 \%, P=0.045$ ). There was no difference in mortality between the groups (HEM 4\% vs. LEM 1\%, $P=0.367$ ). Table 3 summarizes our injury, procedure, and outcome data. Table 4 summarizes the FF procedures performed.

\section{Discussion}

FFs can occur after a wide variety of mechanisms. Injuries concomitant to FFs can often be significant, and complicate clinical management and patient recovery after trauma. Our analysis of 123 patients with FFs after both high and low MOIs showed similar fracture pattern rates and need for facial operations, but significant differences in associated injuries and the complexity of care required to manage them.

When comparing the types of fracture patterns that occurred between the HEM and LEM groups, we found no significant differences in fracture rates based on facial region, bilaterality, or those with Le Fort architecture. Additionally, we found no difference in facial surgery rates or time to facial surgery. Prior to this analysis, we would have predicted that HEM patients would have more severe facial injuries, and subsequently would require operative management more often. Furthermore, we suspected that definitive facial repair would be delayed until later in the hospital course as higher priority injuries were managed first. Analysis of our data, however, suggests that none of these conjectures are valid. Though the HEM group had a higher burden of injury and an overall higher need for procedures, these same findings are not reflected in the types of injuries, timing, or procedures needed to manage facial injuries. The underlying biomechanics of the facial bones lend themselves to predictable fracture patterns, 
Table 3 Facial fracture location, associated injuries, and procedures

\begin{tabular}{|c|c|c|c|}
\hline & \multicolumn{2}{|c|}{ Energy mechanism } & \multirow[t]{2}{*}{$P$ value } \\
\hline & Low $(n=98)$ & High $(n=25)$ & \\
\hline \multicolumn{4}{|l|}{ Fracture location } \\
\hline Upper third (\%) ${ }^{1}$ & $13(13)$ & $6(24)$ & 0.217 \\
\hline Midface $(\%)^{1}$ & $62(63)$ & $21(84)$ & 0.057 \\
\hline Mandible $(\%)^{1}$ & $37(38)$ & $5(20)$ & 0.105 \\
\hline Bilateral (\%) ${ }^{1}$ & $17(17)$ & $8(32)$ & 0.161 \\
\hline Le Fort (\%) ${ }^{1}$ & $3(3)$ & $3(12)$ & 0.098 \\
\hline Multiple facial fractures ${ }^{1}$ & $45(46)$ & $15(60)$ & 0.264 \\
\hline \multicolumn{4}{|l|}{ Associated injuries } \\
\hline Any head or neck injury $(\%)^{1}$ & $35(36)$ & $17(68)$ & 0.265 \\
\hline Intracranial hemorrhage $(\%)^{1}$ & $15(15)$ & $13(52)$ & $<0.001^{*}$ \\
\hline Cerebrovascular $(\%)^{1}$ & $0(0)$ & $0(0)$ & NA \\
\hline Concussion (\%) & $33(34)$ & $14(56)$ & 0.064 \\
\hline Cervical spine fracture (\%) ${ }^{1}$ & $0(0)$ & $3(12)$ & $<0.001^{*}$ \\
\hline Any torso or extremity injury $(\%)^{1}$ & $7(7)$ & $16(64)$ & $0.0453^{*}$ \\
\hline Thoracic $(\%)^{1}$ & $5(5)$ & $14(56)$ & $<0.001^{*}$ \\
\hline Abdominal $(\%)^{1}$ & $0(0)$ & $2(8)$ & $0.040^{*}$ \\
\hline Pelvic/lower extremity (\%) ${ }^{1}$ & $1(1)$ & $6(24)$ & $<0.001^{*}$ \\
\hline \multicolumn{4}{|l|}{ Procedures } \\
\hline $\mathrm{CTA}^{2}$ performed $(\%)^{1}$ & $5(5)$ & $9(36)$ & $<0.001^{*}$ \\
\hline Any procedure (\%) ${ }^{1}$ & $48(49)$ & $18(72)$ & $0.045^{*}$ \\
\hline Neurosurgical procedure (\%) ${ }^{1}$ & $5(5)$ & $7(28)$ & $0.002^{*}$ \\
\hline Facial surgery required (\%) ${ }^{1}$ & $39(40)$ & $7(28)$ & 0.357 \\
\hline
\end{tabular}

${ }^{1}$ Fisher's exact $T$ test

${ }^{2}$ Computed tomography angiography

but whether highly variable MOIs as seen in our analysis generate traumatic forces similar enough to fracture these bones similarly is unclear; our data suggests this may be the case, but clearly a dedicated study with a larger sample size is warranted to further explore these findings [2].

Over half of our LEM patients tested positive for ethanol in contrast to only $22 \%$ of our HEM patients. Prior studies have recognized ethanol use as a common feature of patients at the time of facial trauma, but the higher prevalence in patients with FFs after LEMs compared to HEMs has not been reported [11,12]. Given the two most common MOIs for the LEM group were assaults and groundlevel falls, our findings further implicate ethanol use as an important factor in these MOIs, and may offer an opportunity for targeted injury-prevention strategies. Our LEM patients had very low rates of injuries "below the clavicles" (only $7 \%$ of patients), but $15 \%$ had ICHs, and $34 \%$ had concussion symptoms. Over $13 \%$ of LEM patients required ICU admission with a mean ICU LOS of 4 days. These findings speak to the possibilities of serious neurological injuries associated with FFs after seemingly minor
Table 4 Procedure summary

\begin{tabular}{|c|c|c|}
\hline & Low energy $(n=39)$ & High energy $(n=7)$ \\
\hline IMF/closed only (\%) & $8(21)$ & $0(0)$ \\
\hline $\begin{array}{l}\text { IMF mandible ORIF } \\
\text { unilateral (\%) }\end{array}$ & $11(28)$ & $1(14)$ \\
\hline $\begin{array}{l}\text { IMF mandible ORIF } \\
\text { bilateral (\%) }\end{array}$ & $7(18)$ & $2(29)$ \\
\hline $\begin{array}{l}\text { Mandible ORIF } \\
\text { unilateral (\%) }\end{array}$ & $3(8)$ & $0(0)$ \\
\hline $\begin{array}{l}\text { Mandible ORIF } \\
\text { bilateral (\%) }\end{array}$ & $4(10)$ & $0(0)$ \\
\hline Zygoma ORIF (\%) & $2(5)$ & $1(14)$ \\
\hline Orbital floor ORIF (\%) & $2(5)$ & $0(0)$ \\
\hline $\begin{array}{l}\text { Zygoma and orbital } \\
\text { floor (\%) }\end{array}$ & $1(3)$ & $0(0)$ \\
\hline $\begin{array}{l}\text { Le Fort ORIF } \\
\text { (multiple) (\%) }\end{array}$ & $0(0)$ & $0(0)$ \\
\hline $\begin{array}{l}\text { Le Fort ORIF } \\
\text { (multiple) and IMF (\%) }\end{array}$ & $1(3)$ & $2(29)$ \\
\hline Frontal sinus ORIF (\%) & $0(0)$ & $1(14)$ \\
\hline
\end{tabular}

IMF intermaxillary fixation, ORIF open reduction internal fixation 
MOIs. This is particularly true in the setting of concomitant ethanol use at the time of injury which can potentially cloud patient evaluation and should serve to heighten the need to aggressively screen these patients for intracranial, craniofacial, cervical, and cerebrovascular injuries. Given the low prevalence of torso/extremity injuries, routine radiological imaging may not be necessary in patients with FFs after LEM unless a clear indication exists; validation of our findings with a multicenter analysis is warranted.

Patients suffering from FFs after HEMs often had severe concomitant injuries complicating their care. Fifty-two percent had ICHs, nearly half of whom required neurosurgical procedures to manage these injuries. In addition to these neurological injuries, HEM patients had nine times the rates of torso and extremity injuries compared to LEM patients (HEM 64\% vs. LEM 7\%, $P=0.045$ ). Correspondingly, HEM patients had nearly double the mean ISS, were admitted to the ICU five times as often, and had an average ICU LOS 8 days longer than their LEM counterparts. Patients with FFs from HEMs were considerably more injured and required longer and more complex medical care. Given these findings, aggressive detection of the head, neck, torso, and extremity injuries and subsequent early transfer to an advanced trauma center for management are warranted.

While there was no significant difference in fracture patterns or FF procedure rates between the two groups, the profile of FF procedures differed. Procedures performed in the LEM population were almost exclusively for the treatment of mandibular fracture (85\%) compared to only $45 \%$ of facial procedures performed in the HEM patients. Unfortunately, given the small number of procedures performed, deeper analysis of differences in FF procedures performed is difficult in our data. Corresponding to the higher rates of non-craniofacial injuries, the HEM group required higher rates of procedures to manage these injuries. Interestingly, despite the greater injury burden, procedures required, and longer hospital course, we found no differences in mortality between the two groups. This finding suggests that, despite the higher burdens of injury and more complex hospital courses in these patients, their life-threatening injuries were appropriately detected and managed. These findings support the need for proactive detection of concomitant injuries and the subsequent multidisciplinary management of these patients at highquality trauma systems.

Our study has several important limitations. This was a retrospective review of a prospectively maintained trauma database and so is vulnerable to errors in data coding and retrieval. SBCH is the only ACS-verified Level-I Trauma Center for the Santa Barbara County region, and though the majority of FFs in our area are referred to us, we were not able to capture those patients to whom referral was not offered, or those refusing transfer from remote hospitals; the impact these patients have on our understanding of FFs in our region is not known. We were not able to evaluate other intoxicants beyond ethanol in our review; clearly, this information would deepen our understanding of the role that intoxication may play in these injuries and may serve as a topic for dedicated study. Only seven HEM patients required operative fixation of their FFs in contrast to 39 patients in the LEM. These small numbers severely hampered our ability to conduct deeper analysis into differences in the types of procedures required, and we are unable to draw conclusions to this question. We did not independently audit the treatment decisions made (operative vs. nonoperative, nor the type of operation performed), and as such, we are unable to comment on the overall absolute rates of operative intervention. The majority of fractures in both groups were managed nonoperatively, and no difference in the relative rates of operative intervention was found; we are unable to draw any further conclusions in regards to the rates of operations in our study population. Lastly, this was a single-institution study of FFs occurring in the Santa Barbara County region; our data analysis is limited by the small patient population, and so leaves us vulnerable to type II statistical error. The body of literature regarding FFs would benefit from a dedicated multicenter analysis.

\section{Conclusion}

FFs after HEM events were associated with severe and multifocal injuries. FFs after LEM events were associated with $\mathrm{ICH}$, concussions, and cervical spine fractures. Mechanism-based screening strategies will allow for the appropriate detection and management of injuries that occur concomitant to FFs.

\section{Abbreviations \\ FF: Facial fracture; HEM: High-energy mechanism; LEM: Low-energy mechanism; MOls: Mechanisms of injury; ICH: Intracranial hemorrhage; SBCH: Santa Barbara Cottage Hospital; ISS: Injury Severity Score; LOS: Length of stay; ICU: Intensive care unit; HD: Hospital day; GCS: Glasgow Coma Scores}

\section{Acknowledgements}

The authors wish to acknowledge Ms. Liliana Limon for her assistance in registry data extraction.

\section{Authors' contributions}

Study design: CSH, AJ, SK, RS. Literature search: AJ, CSH, RS. Data collection: $\mathrm{CSH}, \mathrm{CL}, \mathrm{HA}, \mathrm{NF}$. Data analysis: AJ, CSH, RS. Writing: RS, AJ, CSH. Critical revision: $\mathrm{RS}, \mathrm{AJ}, \mathrm{CSH}, \mathrm{SK}$. The authors read and approved the final manuscript.

\section{Funding}

None.

\section{Availability of data and materials}

The datasets generated for the current study are not publicly available as they contain health information protected under the U.S. Health Insurance Portability and Accountability Act of 1996 but are available upon reasonable request.

Ethics approval and consent to participate

This study received Institutional Review Board Approval at Santa Barbara Cottage Hospital. 


\section{Consent for publication}

Not applicable.

\section{Competing interests}

The authors declare that they have no competing interests.

Received: 24 February 2020 Accepted: 31 May 2020

Published online: 24 June 2020

\section{References}

1. Gartshore $L$ (2010) A brief account of the life of René Le Fort. Br J Oral Maxillofac Surg 48(3):173-175. https://doi.org/10.1016/j.bjoms.2009.09. 003

2. Pappachan B, Alexander M (2011) Biomechanics of cranio-maxillofacial trauma. J Maxillofac Oral Surg 11(2):224-230. https://doi.org/10.1007/ s12663-011-0289-7

3. Beogo R, Dakoure P, Savadogo L, Coulibaly A, Ouoba K (2013) Associated injuries in patients with facial fractures: a review of 604 patients. Pan Afr Med J 16(119). https://doi.org/10.11604/pamj.2013.16.119.3379

4. Le TT, Oleck NC, Khan W, Halsey JN, Liu FC, Hoppe IC, Lee ES, Granick MS (2019) Implications of facial fracture in airway management of the adult population. Annals Plastic Surg 82(4S Suppl 3):S179-184. https://doi.org/ 10.1097/sap.0000000000001883

5. Hohlrieder M, Hinterhoelzl J, Ulmer H, Lang C, Hackl W, Kampfl A, Benzer A, Schmutzhard E, Gassner R (2003) Traumatic intracranial hemorrhages in facial fracture patients: review of 2,195 patients. Intensive Care Med 29(7):1095-1100. https://doi.org/10.1007/s00134-003-1804-1

6. Abosadegh M, Rahman S, Saddki N (2017) Association of traumatic head injuries and maxillofacial fractures: a retrospective study. Dent Traumatol 33(5):369-374. https://doi.org/10.1111/edt.12349

7. Joshi U, Ramdurg S, Saikar S, Patil S, Shah K (2018) Brain injuries and facial fractures: a prospective study of incidence of head injury associated with maxillofacial trauma. J Maxillofac Oral Surg 17(4):531-537. https://doi.org/ 10.1007/s12663-017-1078-8

8. Haider AH, Chang DC, Haut ER, Cornwell EE, Efron DT (2009) Mechanism of injury predicts patient mortality and impairment after blunt trauma. J Surg Res 153(1):138-142. https://doi.org/10.1016/j.jss.2008.04.011

9. United States Congress (2010) Initiative to reduce unnecessary radiation exposure from medical imaging, U.S. Food and Drug Administration, Center for Devices and Radiological Health. https://www.fda.gov/ radiation-emitting-products/radiation-safety/initiative-reduceunnecessary-radiation-exposure-medical-imaging. Accessed 21 Jan 2020

10. R Core Team (2018) R: a language and environment for statistical computing. R Foundation for Statistical Computing, Vienna, Austria. http://www.R-project.org/

11. Rao S, Paramesh R, Bansal A, Shukla D, Sadashiva N, Saini J (2019) A prospective computed tomography study of maxillofacial injuries in patients with head injury. Eur J Trauma Emerg Surg Mar 12. https://doi. org/10.1007/s00068-019-01099-0. Accessed 19 Dec 2019

12. Pham T, Lester E, Grigorian A, Roditi R, Nahmias J (2019) National analysis of risk factors for nasal fractures and associated injuries in trauma. Craniomaxillofac Trauma Reconstr 12:221 -227. https://doi.org/10.1055/ s-0039-1677724

\section{Publisher's Note}

Springer Nature remains neutral with regard to jurisdictional claims in published maps and institutional affiliations.

\section{Submit your manuscript to a SpringerOpen ${ }^{\circ}$ journal and benefit from:}

- Convenient online submission

- Rigorous peer review

- Open access: articles freely available online

- High visibility within the field

- Retaining the copyright to your article

Submit your next manuscript at $>$ springeropen.com 